\title{
GRAPHENE OXIDE FUNCTIONALIZED BY ETHYLENE DIAMINE TETRA- ACETIC ACID (EDTA) BY A HYDROTHERMAL PROCESS AS AN ADSORBENT FOR NICKEL IONS
}

\author{
HEBAT-ALLAH S. TOHAMY, SAMIR KAMEL and MOHAMED EL-SAKHAWY \\ National Research Centre, Cellulose and Paper Department, 33 El-Bohouth Str., \\ Dokki, P.O. 12622, Giza, Egypt \\ Corresponding author: M. El-Sakhawy, elsakhawy@yahoo.com
}

Received November 29, 2020

Graphene oxide (GO) from sugar cane bagasse (SCB/F) was treated with EDTA to produce modified GO (EGO) by a hydrothermal preparation reaction. Raman spectra showed an intensity ratio of $\mathrm{I}_{\mathrm{D}} / \mathrm{I}_{\mathrm{G}}$ for $\mathrm{SCB} / \mathrm{F}$ and $\mathrm{EGO8:1}$ (EDTA:GO 8:1) of 0.598 and 0.391 , respectively. FTIR spectra confirmed the introduction of nitrogen-containing groups into the SCB/F backbone. SEM analysis demonstrated the porosity character for the sample. The TGA/DTA results implied the EGO8:1 sample was less thermally stable than SCB/F. The $\mathrm{Ni}^{2+}$ adsorption study revealed a steadily increasing adsorption of $\mathrm{Ni}^{2+}$ until $45 \mathrm{~min}$, with no noticeable increase in adsorption after that. The results of kinetic modeling, adsorption isotherms, and thermodynamic parameters showed that the pseudo-second-order models gave a better fit to the adsorption data of the SCB/F and EGO samples. Also, the adsorption data fitted the Langmuir model best, and the negative values of $\Delta \mathrm{G}$ indicated that the sorption process was spontaneous.

Keywords: graphene oxide, EDTA, heavy metal ions, Ni (II) ion, adsorption, water pollution

\section{INTRODUCTION}

Contaminated water leads to a global crisis for the environment and human health. Population growth and discharging polluted industrial wastewater negatively affect the environment. Pollutants include toxic and carcinogenic metal ions, which are linked with public health problems, such as diarrhea, cancer, and liver sicknesses. ${ }^{1}$

Several techniques have been investigated for water remediation, such as reverse osmosis, ion exchange, and distillation. However, the practical application of these methods is restricted because of self-contamination and high costs. ${ }^{2}$ It is necessary to utilize economical techniques for water purification. Adsorption processes have the advantages of low cost, lower energy requirements and high efficiency. Thermodynamic parameters, adsorption capacities, and adsorption rates can be determined using the batch reactor technique for water treatment. $^{3}$

Nanoparticles, specifically those of graphene (G) and graphene oxide (GO), have the ability to perform as economically viable adsorbents, which makes them a good choice for the adsorption of water pollutants. ${ }^{3}$ Graphene based and conventional adsorbents are an economical choice when they are produced from eco-friendly, biodegradable and renewable lignocellulosic agricultural wastes. ${ }^{4}$

Graphene oxide (GO) is a partially oxidized form of a monolayer $G$ sheet, with hydrophilic oxygen-containing functional groups, large surface area, and excellent mechanical properties. ${ }^{5}$ Hummers introduced a proper method to prepare $\mathrm{GO}$ using $\mathrm{H}_{2} \mathrm{SO}_{4}$ and $\mathrm{KMnO}_{4}{ }^{1} \mathrm{GO}$ forms a stable dispersion of single-layered $\mathrm{GO}$ sheets in polar organic solvents to provide enhanced surface attraction during the fabrication of nanocomposites. ${ }^{6}$

Chemical modifications of $\mathrm{GO}$ are used to improve its properties and to minimize the cohesive force between the $\mathrm{G}$ sheets. ${ }^{7}$ Ethylene diamine tetra-acetic acid (EDTA) reacts with GO to maximize its adsorption capacity for metal ion removal. ${ }^{8}$ Oxygen-containing functional groups, together with EDTA groups, make EDTA-GO efficient adsorbents for the removal of heavy 
metal ions from wastewater. Introducing ethylene diamine tetra-acetic acid (EDTA) to the GO surface offers superior adsorption capacity towards $\mathrm{Pb}$ (II) ions. ${ }^{9}$ GO-based materials have been widely used in water purification owing to their strong adsorption efficiency and low cost. ${ }^{7,10}$

Removing $\mathrm{Ni}$ (II) ions from polluted wastewaters to protect the environment, using eco-friendly, economical adsorbents, is the aim of this study. For commercial applications, it is highly desirable to develop a simple, fast and cost-effective method to prepare useful functionalized GO adsorbents. Employing bagasse in GO preparation improves profitability, raising the added value of this residue, and reduces the harmful practice of burning agricultural wastes. Hence, it is a novel strategy for the development of efficient adsorbents from agricultural residues, which is promising from both economical and sustainability viewpoints.

\section{EXPERIMENTAL \\ Materials}

Sugarcane bagasse (SCB) was kindly provided by Quena Company for Paper Industry, Egypt. The bagasse was air-dried, homogenized to avoid compositional differences between batches and ground to a mesh size of 450 micron. Ferrocene $(\mathrm{F})$ was purchased from Sisco Research Laboratories Pvt. Ltd. Other chemicals used were of analytical grade and used without further purification.

\section{Synthesis of graphene oxide (GO) from bagasse}

$\mathrm{GO}$ was firstly prepared by oxidation of SCB with $\mathrm{F}$ at $300{ }^{\circ} \mathrm{C}$ in a muffled condition. A mixture of $0.5 \mathrm{~g}$ of SCB with $0.1 \mathrm{~g}$ of $\mathrm{F}$ was charged into a muffle furnace at $300{ }^{\circ} \mathrm{C}$ for 10 min under atmospheric conditions. $^{7,10}$ In another trial, GO was prepared without F. The prepared GO samples were denoted as $\mathrm{SCB} / \mathrm{F}$.

Preparation of GO functionalized with ethylene diamine tetra-acetic acid (EDTA)

GO-EDTA nanoparticles were prepared using the hydrothermal process of EDTA in the presence of SCB/F. $0.8 \mathrm{~g}$ of $\mathrm{GO}$ in $400 \mathrm{~mL}$ of $\mathrm{H}_{2} \mathrm{O}$ was ultrasonicated for $1 \mathrm{~h}$. At the same time, the precursor EDTA solution (appropriate amount of EDTA in 100 $\mathrm{mL}$ of methanol) was stirred to attain a homogenous solution. After that, the EDTA solution was added to the GO suspension and stirred for $24 \mathrm{~h}$ at $60{ }^{\circ} \mathrm{C}$. At the end of the reaction, $200 \mathrm{~mL}$ of methanol was added to remove the unreacted molecules. The product was separated by centrifugation, followed by washing with distilled water and methanol twice. Then, it was dried in an oven at $60^{\circ} \mathrm{C}$. The obtained product was denoted as GO-EDTA. The GO-EDTA nanoparticles were prepared by varying the weight ratio between $\mathrm{GO}$ and EDTA (EDTA:GO $=2: 1,4: 1,6: 1,8: 1$ and 10:1) and denoted as EGO 2:1, EGO 4:1, EGO 6:1, EGO 8:1 and EGO 10:1, respectively.

\section{FTIR spectra analysis}

Infrared spectra were recorded with a Jasco FT/IR, Nicolet, Model 670, in the region from 4000 to 400 $\mathrm{cm}^{-1}$. The absorbance intensities at $1420-1430 \mathrm{~cm}^{-1}$ and $900 \mathrm{~cm}^{-1}$ are the characteristic bands of the crystalline and amorphous structure of the samples, respectively. The ratio between these two bands was defined as the empirical crystallinity index (LOI). From the IR spectra, the mean hydrogen bond strengths (MHBS) were determined according to the relation:

$\mathrm{MHBS}=\frac{\mathrm{AOH}}{\mathrm{ACH}}$

Thermogravimetric analysis (TGA) and differential thermogravimetric analysis (DTG)

TG and DTG curves were recorded by a PerkinElmer Thermal Analysis Controller AC7/DX TGA7, using a heating rate of $10{ }^{\circ} \mathrm{C} \min ^{-1}$ in nitrogen atmosphere.

\section{Kinetics of thermal decomposition}

The activation energy (E) can be determined from the thermogravimetric analysis data as follows:

$$
\begin{array}{ll}
\log \left[\frac{1-(1-\alpha)^{1-n}}{\mathrm{~T}^{2}(1-\mathrm{n})}\right]=\log \frac{A R}{\beta E}\left[1-\frac{2 R T}{E}\right]-\frac{E}{2.303 R T} & \text { for } \mathrm{n} \neq 1 \\
\log \left[\frac{-\log (1-\alpha)}{\mathrm{T}^{2}}\right]=\log \frac{A R}{\beta E}\left[1-\frac{2 R T}{E}\right]-\frac{E}{2.303 R T} & \text { for } \mathrm{n}=1
\end{array}
$$

where $\alpha$ is the fractional conversion, $\mathrm{n}$ is the order of degradation reaction, $\mathrm{R}$ is the gas constant (in $\mathrm{kJ} / \mathrm{mol}$. $\mathrm{K}$ ), $\mathrm{T}$ is the temperature (in $\mathrm{K}$ ), $\mathrm{A}$ is the frequency factor $\left(\mathrm{s}^{-1}\right), B$ is the heating rate $(\mathrm{K} / \mathrm{min})$ and $\mathrm{E}$ is the activation energy. From the above equation, plotting the left-hand side of Eq. (2) against 1/T, using different $\mathrm{n}$ values, should offer a straight line, with the most proper value of $\mathrm{n}$. Thus, the method of the least squares was applied for the equation, taking various $n$ values (from 0 to 3.0) and calculating for each value of $\mathrm{n}$, the correlation coefficient $\left(\mathrm{R}^{2}\right)$, and standard error estimation (SE).

The activation energies were estimated from the slope (E/2.303R), while $A$ was estimated from the intercept $(\log A R / B E)$ of the Coats-Redfern equation with the most proper value of $n .{ }^{11}$ The other kinetic parameters: the enthalpy of activation $(\Delta \mathrm{H})$, the entropy of activation $(\Delta S)$ and the free energy change of activation $(\Delta \mathrm{G})$, were calculated using the relationship:

$\Delta H^{*}=E^{*}-R T ; \Delta G^{*}=\Delta H^{*}-T \Delta S^{*}$ and $\Delta S^{*}=2.303\left(\log \frac{A h}{K T}\right)_{(4)}$

where $(\mathrm{k})$ and $(\mathrm{h})$ are Boltzman and Planck constants, respectively. ${ }^{4}$ 


\section{$X$-ray diffraction analysis}

Diffraction patterns were obtained using a Bruker D8 Advance X-ray Diffractometer (Germany). The diffraction patterns were recorded using a copper $(\mathrm{K} \alpha)$ target with a secondary monochromator at $40 \mathrm{kV}$ and $40 \mathrm{~mA}$. The crystallinity index (CrI) was calculated via:

$$
\begin{aligned}
& \mathrm{CrI}(\%)=\frac{\mathrm{Sc}}{\mathrm{St}} \times 100 \\
& \Delta \mathrm{CrI}(\%)=\frac{\text { CrI modified GO-CrI pure Go }}{\text { CrI modified GO }} \times 100
\end{aligned}
$$

where $\mathrm{Sc}=$ area of the crystalline domain, $\mathrm{St}=$ area of the total domain, $\Delta \mathrm{CrI}(\%)=$ change of crystallinity.

The distance of GO interlayer ( $\left.d_{\text {spacing }}\right)$ was

calculated using Bragg's law:

$d_{\text {spacing }}(\mathrm{nm})=\frac{\lambda}{2 \sin \theta} \times 100$

where $\theta=$ Bragg's angle in radians, $\lambda=\mathrm{X}$-ray wavelength $(0.1542 \mathrm{~nm})$.

The crystallite size can be calculated by using Scherrer's equation:

Crystal size $(\mathrm{nm})=\frac{0.9 \lambda}{\beta \cos \theta}$

where $\lambda$ is the wavelength of X-rays, $\beta$ and $\theta$ are full widths at half maxima and Bragg's angle of the XRD peak, respectively.

\section{Scanning electron microscopy (SEM) and energy dispersive X-ray spectroscopy (EDX)}

Scanning electron microscopy (gold coating, Edwards Sputter Coater, UK) was performed using a Jeol 6310 (Jeol Instruments, Tokyo, Japan) system, running at 5-10 keV. Energy dispersive X-ray spectroscopy (EDX) was conducted using the EDX unit attached to the SEM.

\section{Transmission electron microscopy (TEM)}

The morphological features of the samples were analyzed with a Philips (CM/TEM) Transmission Electron Microscope.

\section{Raman spectroscopy}

Raman spectroscopy was performed using a WITEC Focus Innovations Alpha-300 Raman Confocal Microscope. The spectra were recorded with a $532 \mathrm{~nm}$ excitation wavelength. A Perkin Elmer 3110 Atomic Absorption Spectrometer, USA, was used to quantify the amount of metal ions. The crystal diameter could be calculated using the relation:

Crystal diameter $(\mathrm{nm})=\left(2.4 \times 10^{-10}\right) \lambda^{4}\left(\frac{I G}{I D}\right)$

where $\lambda$ is the wavelength of the laser, and $I_{G}, I_{D}$ are the intensities of G- and D- bands, respectively. ${ }^{12}$

\section{$\mathrm{Ni}^{2+}$ adsorption study}

Adsorption suspensions were prepared by adding $20 \mathrm{mg}$ of adsorbents in $20 \mathrm{~mL}$ of $\mathrm{Ni}^{2+}$ solution with known initial concentration $(15 \mathrm{mg} / \mathrm{L})$ and stirred for different time intervals to study the effect of contact time.

The effect of temperature on the adsorption capacity of $\mathrm{Ni}^{2+}$ on the adsorbent surface was elucidated from 298 to $328 \mathrm{~K}$. All adsorption experiments were performed at a contact time of 30 min. The removal experiments were performed using various initial concentrations: $15,20,25$ and $30 \mathrm{mg} / \mathrm{L}$, at $30 \mathrm{~min}$ contact time and $298 \mathrm{~K}$, to study the effect of $\mathrm{Ni}^{2+}$ ion initial concentration. The final metal ion concentrations were measured using an atomic absorption spectrophotometer and the removal efficiency percent (R \%) of the sorbents toward metal ions was calculated.

\section{Kinetic modeling}

To achieve the controlling rate mechanism of the adsorption processes, such as mass transfer and chemical reaction, the pseudo-first-order and pseudosecond-order equations are utilized to model the kinetic data of $\mathrm{Ni}^{2+}$ adsorption onto the adsorbent surfaces. $^{13}$ The first-order, second-order, and intraparticular diffusion equations were applied to the data derived from the effect of time on adsorption. ${ }^{14}$

(i) The pseudo-first-order reaction model is based on the hypothesis that physisorption is the ratedetermining step and it is given in Equation (10):

$\ln [q e-q t]=\ln q e-K 1 t$

where qe and qt are the amounts of $\mathrm{Ni}^{2+}$ adsorbed $(\mathrm{mg} / \mathrm{g})$ at equilibrium and in time, respectively, $\mathrm{K}_{1}$ $\left(\mathrm{min}^{-1}\right)$ is the pseudo-first-order rate constant of adsorption. ${ }^{13}$

(ii) The pseudo-second-order reaction model is based on the hypothesis that chemisorption is the ratedetermining step and it is given in Equation (11):

$\frac{\mathrm{t}}{\mathrm{qt}}=\frac{1}{\mathrm{~K} 2 \mathrm{qe} 2}+\frac{\mathrm{t}}{\mathrm{qe}}$

where $\mathrm{K}_{2}(\mathrm{~g} / \mathrm{mg} / \mathrm{min})$ is the rate constant of pseudosecond order adsorption. The values of $\mathrm{qe}_{2}$ and $K_{2}$ were calculated from the slope and intercept of the plot of $\mathrm{t} / \mathrm{qt}$ against $\mathrm{t}$. In chemisorption (i.e. chemical adsorption), the $\mathrm{Ni}^{2+}$ ions stick to the adsorbent surface by chemical (usually covalent) bonding and prefer to find sites that maximize their coordination number with the surface. ${ }^{15}$

(iii) Intra-particular diffusion is expressed as:

$\mathrm{qt}=\mathrm{k}_{\mathrm{di}} \mathrm{t}^{0.5}+\mathrm{C}_{\mathrm{i}}$

where $\mathrm{k}_{\mathrm{di}}\left(\mathrm{mg} / \mathrm{g} \min ^{0.5}\right)$ is the intra-particle diffusion rate constant of stage $\mathrm{i} ; \mathrm{C}_{\mathrm{i}}(\mathrm{mg} / \mathrm{g})$ is the intercept of stage $i$. The values of $k_{d i}$ and $C_{i}$ can be obtained from the slope and intercept of qt versus $\mathrm{t}^{0.5}$, respectively. 


\section{Adsorption isotherm}

The adsorption isotherm provides information on how the adsorbed molecules are distributed between the liquid phase and the solid phase when the adsorption process reaches an equilibrium state (i.e. the adsorption mechanisms, the surface properties and affinities of the adsorbent). ${ }^{13} \mathrm{R}^{2}$ is used to determine the best-fitting isotherm. In the current study, the adsorption equilibrium data were fitted to the Langmuir and the Freundlich isotherm models. ${ }^{14}$

(i) Langmuir isotherm model: it is based on the vision that every adsorption site is equivalent and independent; the ability of a molecule to bind is independent of whether neighboring sites are occupied. ${ }^{16}$ The Langmuir model is given by Equation (13):

$$
\frac{\mathrm{Ce}}{\mathrm{qe}}=\frac{1}{\mathrm{Kqm}}+\frac{\mathrm{Ce}}{\mathrm{qm}}
$$

where $\mathrm{q}_{\mathrm{m}}(\mathrm{mg} / \mathrm{g})$ is the maximum removal capacity.

(ii) Freundlich model: describes the non-ideal and reversible adsorption (i.e. an infinite supply of unreacted adsorbent sites) and preferably represents heterogeneous materials, compared to other models. ${ }^{17}$ The Freundlich model is given by Equation (14):

$\log \mathrm{qe}=\log \mathrm{Kf}+\frac{1}{\mathrm{n}} \log \mathrm{Ce}$

where $\mathrm{K}_{\mathrm{f}}$ is the adsorption capacity.

The Langmuir isotherm is restricted to the formation of a monolayer, in contrast to the Freundlich isotherm, which can be applied to multilayer adsorption, with non-uniform distribution of the adsorption heat and affinities over the heterogeneous surface. $^{7,17}$

\section{Thermodynamic parameters}

The speed of the reaction can be calculated from the awareness of kinetic studies, but the change in the reaction that can be expected during the process needs knowledge of thermodynamic parameters.

Thermodynamic parameters, such as the Gibbs free energy $(\Delta \mathrm{G}, \mathrm{kJ} / \mathrm{mol})$, enthalpy $(\Delta \mathrm{H}, \mathrm{kJ} / \mathrm{mol})$, and entropy $(\Delta \mathrm{S}, \mathrm{kJ} / \mathrm{mol})$ changes during adsorption can be estimated from Equation (15) of Van't Hoff: ${ }^{18}$

$$
\ln \mathrm{Kd}=\frac{\Delta \mathrm{S}}{\mathrm{R}}-\frac{\Delta \mathrm{H}}{\mathrm{RT}}
$$

where $\mathrm{T}$ is the temperature in Kelvin, and $\mathrm{R}$ is the universal gas constant $\left(8.314 \mathrm{~J} \mathrm{~mol}^{-1} \mathrm{~T}^{-1}\right)$. The distribution coefficient $\left(\mathrm{K}_{\mathrm{d}}\right)$ on GO surface was calculated using Equation (16):

$\mathrm{K}_{\mathrm{d}}=\frac{\mathrm{Ci}-\mathrm{Ce}}{\mathrm{Ce}} \times \frac{\mathrm{V}}{\mathrm{m}}$

The Gibbs free energy can be calculated using Equation (17):

$\Delta \mathrm{G}=-\mathrm{RT} \ln \mathrm{K}_{\mathrm{d}}$

The values of $\Delta \mathrm{H}$ and $\Delta \mathrm{S}$ can be obtained from the slope and intercept of Van't Hoff plot of $\operatorname{lnK}$ versus $1 / \mathrm{T}^{19}$

\section{RESULTS AND DISCUSSION Percentage yield \%}

The yield of EGO nanocomposite is presented in Table 1. From the table, it could be noticed that the yield of EGO increased with increasing the EDTA content. The yield increased compared with the original GO weight used by 130,453 , 709 and 846\% for EGO4:1, EGO6:1, EGO8:1 and EGO10:1, respectively.

\section{Raman spectroscopy}

Figure 1 shows the Raman spectra of $\mathrm{SCB} / \mathrm{F}$ and EGO8:1 synthesized from sugarcane bagasse raw material. The G-band is located at 1582 and $1588 \mathrm{~cm}^{-1}$ for SCB/F and EGO8:1, respectively. The characteristic D-bands (arising from the stretching of $\mathrm{sp}^{3}$ carbons of graphene sheets) are located at 1378 and $1352 \mathrm{~cm}^{-1}$ for $\mathrm{SCB} / \mathrm{F}$ and EGO8:1, respectively. ${ }^{20,21}$ From the ID/IG ratio, the structural disorder in $\mathrm{SCB} / \mathrm{F}$ and $\mathrm{EGO}: 1 \mathrm{can}$ be characterized. Table 2 shows that the $\mathrm{I}_{\mathrm{D}} / \mathrm{I}_{\mathrm{G}}$ ratio for $\mathrm{SCB} / \mathrm{F}$ and $\mathrm{EGO}: 1$ is 0.598 and 0.391 , respectively. The higher value for $\mathrm{SCB} / \mathrm{F}$ may be due to the presence of more defects, compared with that of EGO8:1.

Table 1

Yield $\%$ of prepared materials

\begin{tabular}{lccccc}
\hline Sample & EGO 2:1 & EGO 4:1 & EGO 6:1 & EGO 8:1 & EGO 10:1 \\
\hline Yield \% & 37 & 130 & 453 & 709 & 846 \\
\hline
\end{tabular}

Table 2

Raman spectra peak positions, and $\mathrm{I}_{\mathrm{D}} / \mathrm{I}_{\mathrm{G}}$ values of the prepared samples

\begin{tabular}{lcccc}
\hline Sample & $\begin{array}{c}\text { D-band } \\
\left(\mathrm{cm}^{-1}\right)\end{array}$ & $\begin{array}{c}\text { G-band } \\
\left(\mathrm{cm}^{-1}\right)\end{array}$ & $\begin{array}{c}\text { FWHM G-band } \\
\left(\mathrm{cm}^{-1}\right)\end{array}$ & $\mathrm{I}_{\mathrm{D}} / \mathrm{I}_{\mathrm{G}}$ \\
\hline SCB/F & 1378 & 1582 & 92 & 0.598 \\
EGO8:1 & 1352 & 1588 & 206.5 & 0.391 \\
\hline
\end{tabular}


The defects here refer to any disorder in the $\mathrm{G}$ backbone structure, such as unreacted hydroxyl and/or epoxy groups on the surface of SCB/F. ${ }^{22}$ This result has been confirmed by measuring the relative absorbance (RA) of the $\mathrm{OH}, \mathrm{C}=\mathrm{O}, \mathrm{C}-\mathrm{OH}$, and $\mathrm{C}-\mathrm{O}-\mathrm{C}$ absorption bands by FTIR data. On the other hand, the G-band was much wider in the case of the EGO8:1 spectrum, compared with that of SCB/F. This can be attributed to the structural imperfections induced by the attachment of EDTA groups on the surface of $\mathrm{SCB} / \mathrm{F}^{23}$

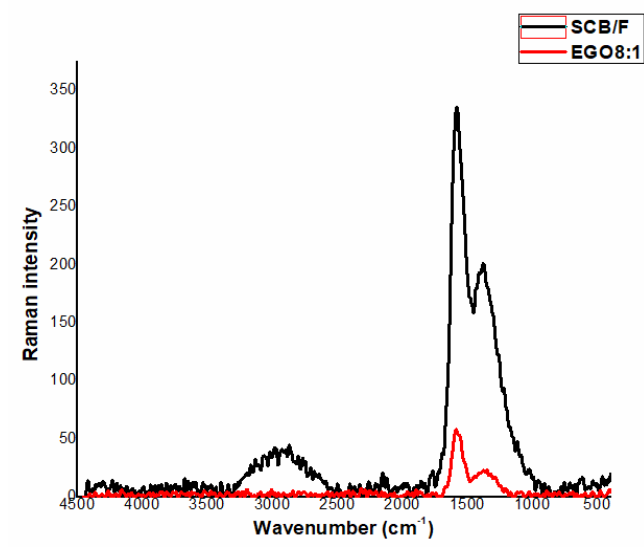

Figure 1: Raman spectra of (a) SCB/F, and (b) EGO8:1

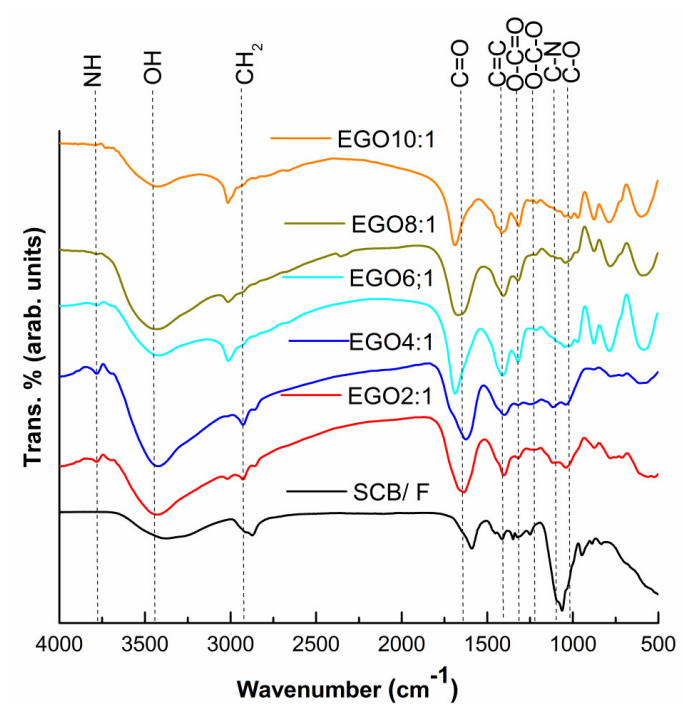

Figure 2: FT-IR spectra of SCB/F, EGO2:1, EGO4:1, EGO6:1, EGO8:1 and EGO10:1

\section{FT-IR analysis}

Figure 2 shows the FT-IR spectra of SCB/F, EGO2:1, EGO4:1, EGO6:1, EGO8:1 and EGO10:1. The peak centered at $1628-1722 \mathrm{~cm}^{-1}$ is attributed to the stretching vibration modes of $\mathrm{C}=\mathrm{O}$, which are located either in the carboxyl and carbonyl groups or on the edge of $\mathrm{GO}^{20}$ Meanwhile the peaks centered at $1408-1618 \mathrm{~cm}^{-1}$ are assigned the $\mathrm{C}=\mathrm{C}$ bonds. ${ }^{20}$ In addition, the bands centered at $880-930 \mathrm{~cm}^{-1}$ are assigned to $\mathrm{C}-\mathrm{O}$ groups. Moreover, the bands that appeared at $961-1156 \mathrm{~cm}^{-1}$ are usually attributed to $\mathrm{C}-\mathrm{O}-\mathrm{C}$ stretching vibrations. ${ }^{24}$ Besides, the bands centered at $13067-1469 \mathrm{~cm}^{-1}$ are assigned to O$\mathrm{C}=\mathrm{O}$ of the carboxyl group. The peak centered at $3410-3450 \mathrm{~cm}^{-1}$ can be attributed to the $\mathrm{O}-\mathrm{H}$ 
stretching vibrations of the $\mathrm{C}-\mathrm{OH}$ groups and water. ${ }^{24}$ Compared with the spectrum of SCB/F, the outstanding difference observed for EGO consists in the bands centered at $3736-3794 \mathrm{~cm}^{-1}$, and 1026-1097 $\mathrm{cm}^{-1}$, which correspond to the vibration of $\mathrm{N}-\mathrm{H}$, and $\mathrm{C}-\mathrm{N}$, respectively. The presence of nitrogen-containing groups demonstrates that EDTA is involved in the formation of $\mathrm{SCB} / \mathrm{F}^{25,26}$

The band at $2991 \mathrm{~cm}^{-1}$ can be attributed to C-H stretching. This band was chosen as an internal standard to determine RA. ${ }^{27}$ The RA of $\mathrm{O}-\mathrm{H}$ is $3.20,0.87,0.87,1.08,1.23$ and 0.49 , while the intensity of $\mathrm{C}=\mathrm{O}$ is $14.70,0.95,0.95,0.59,0.45$ and 0.76, for SCB/F, EGO2:1, EGO4:1, EGO6:1, EGO8:1 and EGO10:1, respectively. On the other hand, the RA of NH is $1.06,1.17,1.74,1.89$ and 0.83 , while $\mathrm{C}-\mathrm{N}$ is $1.06,1.07,1.18,1.83$ and 1.73 for EGO2:1, EGO4:1, EGO6:1, EGO8:1 and EGO10:1, respectively. The RA of the $\mathrm{O}-\mathrm{H}$ and $\mathrm{C}=\mathrm{O}$ absorption bands strongly decreases in EGO. This proves the crosslinking reaction between the $\mathrm{OH}$ group of $\mathrm{SCB} / \mathrm{F}$ and $\mathrm{NH}_{2}$ of EDTA forming an amide bond. ${ }^{26}$
The $\mathrm{OH}$ stretching vibration for $\mathrm{SCB} / \mathrm{F}$ (3441 $\left.\mathrm{cm}^{-1}\right)$ shifted to a lower frequency $(3437,3437$, 3437, 3423 and $3422 \mathrm{~cm}^{-1}$ for EGO2:1, EGO4:1, EGO6:1, EGO8:1 and EGO10:1, respectively) as a result of EDTA grafting to $\mathrm{SCB} / \mathrm{F}$. This change may be due to the intermolecular hydrogen bonding, which decreased upon grafting of $\mathrm{SCB} / \mathrm{F}$ with EDTA. ${ }^{27}$ Measuring the crystallinity indices revealed the higher crystallinity index of SCB/F, since the layers of $\mathrm{G}$ before grafting are still compact, compared to the exfoliated ones after grafting. Upon grafting of EDTA to the SCB/F backbone, the crystallinity index decreased because of the transformation of the crystalline regions in SCB/F into amorphous ones upon the EDTA treatment. In general, the mean hydrogen bond strength $\left(\mathrm{A}_{\mathrm{OH}} / \mathrm{A}_{\mathrm{CH}}\right)$ decreased after the EDTA treatment, owing to the substitution of free $\mathrm{OH}$ groups (Table 3). ${ }^{27}$ Besides, the $\mathrm{C}=\mathrm{O}$ stretching frequency band of SCB/F $\left(1722 \mathrm{~cm}^{-1}\right)$, as a result of its reaction with EDTA groups, was shifted to a lower wavenumber at 16281630 , 1674, 1676 and $1679 \mathrm{~cm}^{-1}$ for EGO2:1, EGO4:1, EGO6:1, EGO8:1 and EGO10:1, respectively.
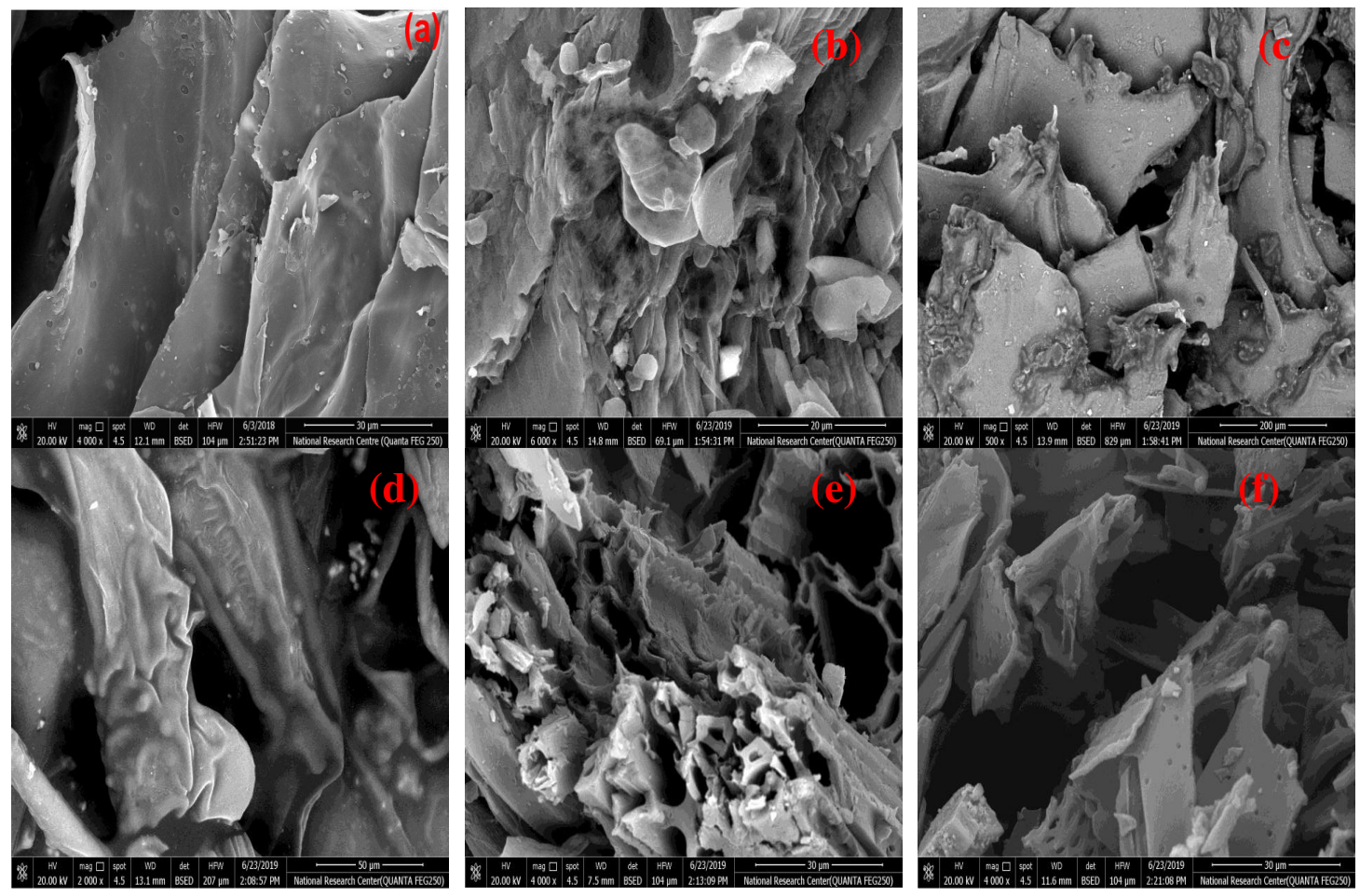

Figure 3: SEM of (a) SCB/F, (b) EGO2:1, (c) EGO4:1, (d) EGO6:1, (e) EGO8:1 and (f) EGO10:1 
Table 3

Empirical crystallinity index and mean H-bond strength of different samples

\section{SEM analysis}

Figure 3 shows the SEM images of the prepared $\mathrm{SCB} / \mathrm{F}$ and $\mathrm{EGO}$ samples. The morphology of the synthesized $\mathrm{SCB} / \mathrm{F}$ samples resembles rounded folds, a cloud and a sheet-like structure with a flat surface. This corrugation of the GO sheets is attributed to the disruption of the planar $\mathrm{sp}^{2}$ carbon sheets by the introduction of $\mathrm{sp}^{3}$-hybridized carbon upon oxidation. The presence of residual $\mathrm{H}_{2} \mathrm{O}$ molecules tightly bound with the carboxyl or hydroxyl group of GO may also lead to this morphology. Meanwhile the rugged surfaces of the EGO2:1, EGO4:1 and EGO6:1 samples can elucidate the distortion of the surface during the drying process. The EGO8:1 sample shows an interlinked structure with a spongy network. This interlinked structure decreases the layer stacking of the SCB/F sheets

$\begin{array}{lc}\text { linity index } & \begin{array}{c}\text { Mean } \mathrm{H} \text {-bond } \\ \text { strength }\left(\mathrm{A}_{\mathrm{OH}} / \mathrm{A}_{\mathrm{CH}}\right)\end{array} \\ 1.14 & 1.60 \\ 0.97 & 0.87 \\ 0.97 & 0.87 \\ 0.65 & 0.88 \\ 0.65 & 0.50 \\ 0.73 & 1.20\end{array}$

and increases the surface area enormously. The morphology image of EGO10:1 shows an obvious structure deprivation, compared with EGO8:1. On the other hand, the pore sizes in the synthesized samples were 250.9, 3624, 56140, 77760, 12850 and $7150 \mathrm{~nm}$ for SCB/F, EGO2:1, EGO4:1, EGO6:1, EGO8:1 and EGO10:1, respectively. Pore size demonstrates the porosity of samples EGO4:1, EGO6:1 and EGO8:1.

EDX analysis shows the weight percentage of different elements found in the samples, as depicted in Figure 4. Generally, the amounts of C and $\mathrm{O}$ elements are higher than that of the $\mathrm{N}$ element in the prepared EGO, while no $\mathrm{N}$ was detected in the $\mathrm{SCB} / \mathrm{F}$ sample. These results reveal that grafting of EDTA to the $\mathrm{SCB} / \mathrm{F}$ backbone was successful.

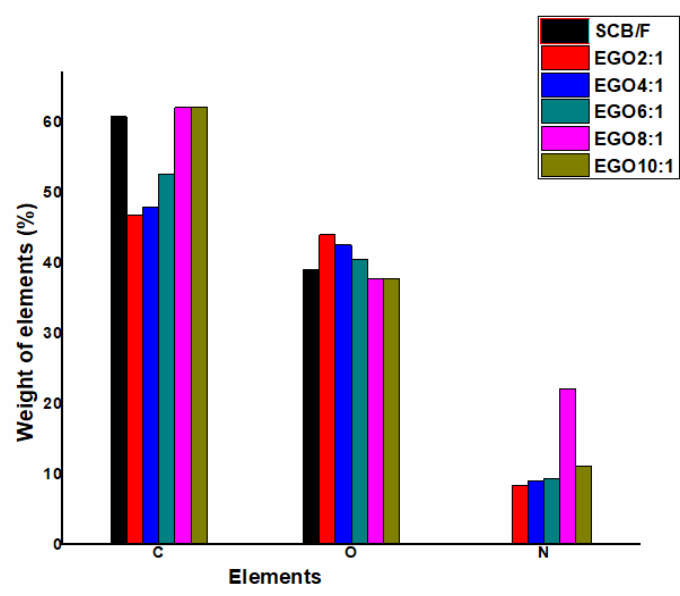

Figure 4: EDX histogram of the prepared samples 
HEBAT-ALLAH S. TOHAMY et al.
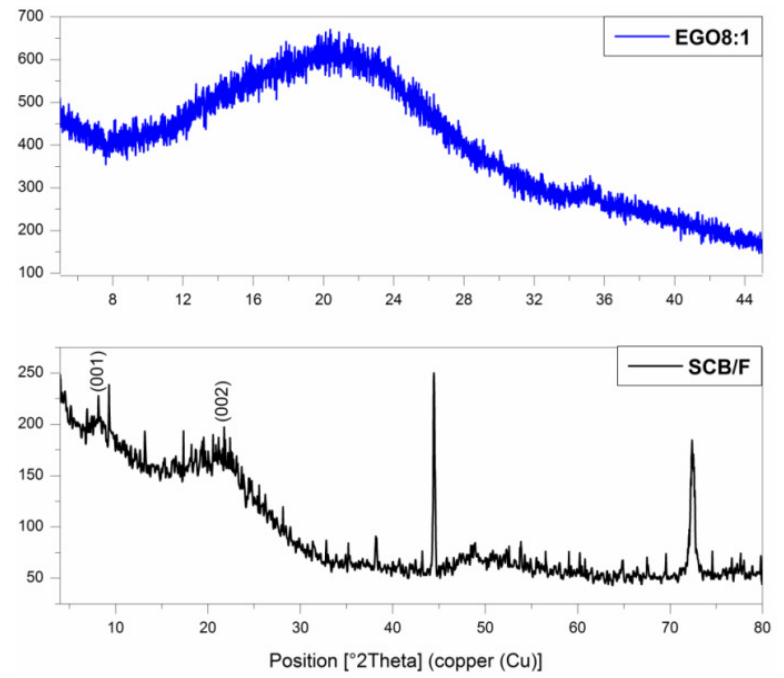

Figure 5: X-ray patterns of SCB/F and S3, respectively

Table 4

X-ray crystallinity index of the prepared samples

\begin{tabular}{lcc}
\hline Sample & CrI (\%) & $\Delta$ CrI $(\%)$ \\
\hline SCB/F & 41.75 & - \\
EGO8:1 & 30.18 & -38.34 \\
\hline
\end{tabular}

\section{XRD analysis}

The crystallinity was analyzed using X-ray diffraction. SCB/F presents an amorphous peak at $2 \theta=9.3^{\circ}$ related to the $(001)$ plane, which is characteristic of $\mathrm{GO}^{22}$ The XRD pattern of $\mathrm{SCB} / \mathrm{F}$ shows the (002) diffraction peak at $2 \theta$ $=21.8^{\circ}$, which indicates incomplete oxidation of SCB. ${ }^{28}$ The two peaks observed at $44.4^{\circ}$ and $72.2^{\circ}$ were attributed to reflections from the aluminum holder used.

As for the pattern of EGO8:1, a broad and weak peak at $2 \theta=20.7^{\circ}$ implies poor ordering of $\mathrm{G}$ sheets, which confirms that the EGO8:1 framework is composed of cross-linked G sheets (Fig. 5). ${ }^{26}$

Table 4 illustrates the variation of $\mathrm{CrI}$ as a function of different functionalizing groups, as calculated from the XRD patterns. It is clear that the crystallinity of EGO8:1 decreased, compared with that of $\mathrm{SCB} / \mathrm{F}$, because the grafting reaction during EGO8:1 preparation leads to cleavage of the hydrogen bonds, which diminishes the crystallinity. ${ }^{20}$ The XRD crystallinity values agree with the mean hydrogen bond values calculated from the IR spectra.

\section{Thermal properties}

The TG/DTG curves for SCB/F and EGO8:1 are given in Figure 6 and Table 5. In general, the decomposition curve of $\mathrm{SCB} / \mathrm{F}$ reveals three decomposition steps, while that of EGO8:1 reveals two decomposition steps. The difference in the chemical composition of $\mathrm{SCB} / \mathrm{F}$ and EGO8:1 causes the observed differences in thermal decomposition behavior and thermal stability. ${ }^{11,30}$ A sudden change in temperature generates a thermal shock, and functionalities, such as water vapor, $\mathrm{CO}$ and $\mathrm{CO}_{2}$, are removed from the GO lattice. The evolution of gases generates pressure between the two GO stacked layers, which is the key factor for exfoliation. ${ }^{31}$ The TG/DTG of SCB/F and EGO8:1 showed a weight loss of 76.8 , and $92.75 \%$, respectively, at $1000{ }^{\circ} \mathrm{C}$, which indicated the presence of a fraction of non-volatile components. ${ }^{11}$ The thermal decomposition process of $\mathrm{SCB} / \mathrm{F}$ was previously recognized. ${ }^{30}$ 

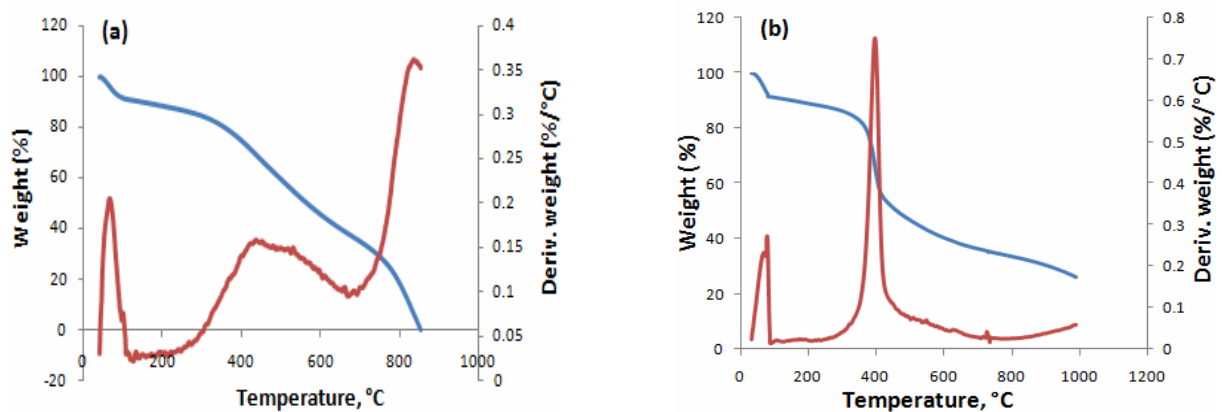

Figure 6: TG and DTG curves of (a) SCB/F and (b) S3, respectively

Table 5

TGA data of SCB/F and EGO8:1

\begin{tabular}{lccccc}
\hline \multirow{2}{*}{ Sample } & Weight loss at & Residual weight, & \multicolumn{3}{c}{ Temperature of steps in TGA, ${ }^{\circ} \mathrm{C}$} \\
\cline { 4 - 6 } & $1000{ }^{\circ} \mathrm{C}, \%$ & $\%$ & Step 1 & Step 2 & Step 3 \\
\hline SCB/F & 76.8 & 23.2 & 64.64 & 431.72 & 836.32 \\
EGO8: 1 & 92.85 & 7.15 & 260.76 & 386.75 & - \\
\hline
\end{tabular}

As shown in Figure 6 (b), the thermal decomposition processes of EGO8:1 could be divided into two major reaction steps. The first weight loss between 246.9-300.1 ${ }^{\circ} \mathrm{C}$, with a maximum at $260.7{ }^{\circ} \mathrm{C}$ (with average weight loss of $67.7 \%$ ), was likely caused by the loss of moisture content and less stable materials. This first weight loss was followed by the main decomposition stage between 352.5-422.5 ${ }^{\circ} \mathrm{C}$, with a maximum at $394.3{ }^{\circ} \mathrm{C}$ (with an average weight loss of $25.0 \%$ ). The main weight loss was assigned to fragmentation associated with the pyrolytic decomposition, leading to the formation of aromatized units and the decomposition of the carbonaceous residues. This latter depolymerization type was considered as the propagation step. ${ }^{11,30}$

The mechanism can be represented as follows:

Initiation: $\mathrm{A}$---------------> $\mathrm{B}_{1}$

Propagation: $\mathrm{B}_{1}------------>\mathrm{B}_{2}+\mathrm{C}$,

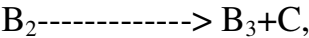

$$
\begin{aligned}
& \mathrm{B}_{\mathrm{n}} \text {------------> } \mathrm{B}_{\mathrm{n}+1}+\mathrm{C} \text {, } \\
& \sum \mathrm{B}_{\mathrm{n}} \text {-----------> } \sum \mathrm{B}_{\mathrm{n}+1}+\mathrm{nC}
\end{aligned}
$$

where A denotes initial molecules of EGO8:1; $\mathrm{B}_{1}$, $\mathrm{B}_{2}, \ldots \mathrm{B}_{\mathrm{n}}$ are fragmented molecules; and $\mathrm{C}$ denotes volatile products. ${ }^{11}$

The conversion of SCB/F into EGO8:1 affects both the molecular structure and the bonding energy, which, in turn, causes the different thermal behavior of $\mathrm{SCB} / \mathrm{F}$ and EGO8:1. The endothermic temperature for EGO8:1 was shifted towards lower values, compared with that of $\mathrm{SCB} / \mathrm{F}$. This shift proves that the EGO8:1 sample was less thermally stable in contrast to $\mathrm{SCB} / \mathrm{F}{ }^{30}$
This may be caused by the decrease of MHS and CrI\% (as discussed in FTIR and XRD sections).

The higher calculated activation energy $\left(\sum \mathrm{E}\right)$ of $\mathrm{SCB} / \mathrm{F}$, compared with that of EGO8:1, confirmed its superior thermal stability (Fig. 7, Table 6). ${ }^{32}$ Finally, the TGA results imply that the mobility of the polymer segments in SCB/F was suppressed by the strong hydrogen bonding interactions between them, resulting in a delay in polymer degradation. Overall, the thermal stability of EGO8:1 decreased, compared to that of pure $\mathrm{SCB} / \mathrm{F}$ without EDTA, confirming the grafting structural changes. SCB/F has higher thermal stability due to its more ordered and packed unexfoliated $\mathrm{G}$ sheets.

\section{$\mathrm{Ni}^{2+}$ adsorption study \\ Effect of contact time}

The adsorption rate increases with increasing the reaction time between the nanocomposites and metal ions. This is explained by the driving forces among the metal ions towards binding.

The SCB/F, EGO2:1, EGO4:1, EGO6:1, EGO8:1 and EGO10:1 samples were examined for the removal of $\mathrm{Ni}^{2+}$ ions. The effect of contact time on adsorption was studied at $\mathrm{Ni}^{2+}$ concentration of $15 \mathrm{mg} / \mathrm{L}$, temperature of $298 \mathrm{~K}$, adsorbent dosage of $20 \mathrm{mg}$, and at different adsorption times (i.e. 15, 30, 45, 60, 75 and 90 min). As shown in Figure 8, the affinity of EGO samples toward $\mathrm{Ni}^{2+}$ ions was different. The removal of $\mathrm{Ni}^{2+}$ by $\mathrm{EGO}$ adsorbents was found to be rapidly increasing initially due to the presence of available active sites. ${ }^{16}$ 
HEBAT-ALLAH S. TOHAMY et al.

Table 6

Thermoanalytical and thermodynamic data of thermal decomposition steps of SCB/F and EGO8:1 samples

\begin{tabular}{|c|c|c|c|c|c|c|c|c|c|c|c|}
\hline Stage & $\begin{array}{c}\text { TG range, } \\
{ }^{\circ} \mathrm{C}\end{array}$ & $\begin{array}{c}\text { DTG peak, } \\
{ }^{\circ} \mathrm{C}\end{array}$ & $\begin{array}{c}\text { Mass loss, } \\
\%\end{array}$ & $n$ & $\mathrm{R}^{2}$ & $\begin{array}{c}\mathrm{A} \\
\left(\mathrm{s}^{-1}\right)\end{array}$ & $\begin{array}{c}\Delta \mathrm{H} \\
\left(\mathrm{Kj} \mathrm{mol}^{-1}\right)\end{array}$ & $\begin{array}{c}\Delta s \\
\left(\mathrm{Kj} \mathrm{mol}^{-1}\right)\end{array}$ & $\begin{array}{c}\Delta \mathrm{G} \\
\left(\mathrm{Kj} \mathrm{mol}^{-1}\right)\end{array}$ & SE & $\begin{array}{c}\mathrm{E} \\
\left(\mathrm{kJ} \mathrm{mol}^{-1}\right)\end{array}$ \\
\hline $1^{\mathrm{st}}$ & $45.11-252.73$ & 64.64 & 13.20 & 0 & 0.999 & 19.5 & -0.06 & -0.221 & 71.35 & $75 \times 10^{-4}$ & 2.63 \\
\hline $2^{\text {nd }}$ & $252.86-627.07$ & 431.72 & 44.18 & 1.5 & 0.995 & 14.3 & 17.30 & -0.223 & 89.55 & $16 \times 10^{-2}$ & 19.99 \\
\hline $3^{\text {rd }}$ & $647.29-855.19$ & 836.32 & 19.42 & 1.5 & 0.995 & 15.2 & 17.71 & -0.253 & 204.68 & $46 \times 10^{-3}$ & $\begin{array}{c}24.45 \\
\sum \mathrm{E}=47.07\end{array}$ \\
\hline $1^{\mathrm{st}}$ & 246.99-300.13 & 260.76 & 67.78 & 0 & 0.999 & 0.99 & -4.37 & -8498.69 & $55 \times 10^{5}$ & $5 \times 10^{-8}$ & $6.83 \times 10^{-5}$ \\
\hline $2^{\text {nd }}$ & $352.56-422.58$ & 394.36 & 25.07 & 1.5 & 0.995 & 3.27 & 11.94 & -0.237 & 106.39 & $15 \times 10^{-2}$ & $\begin{array}{c}15.25 \\
\sum \mathrm{E}=5.25\end{array}$ \\
\hline
\end{tabular}
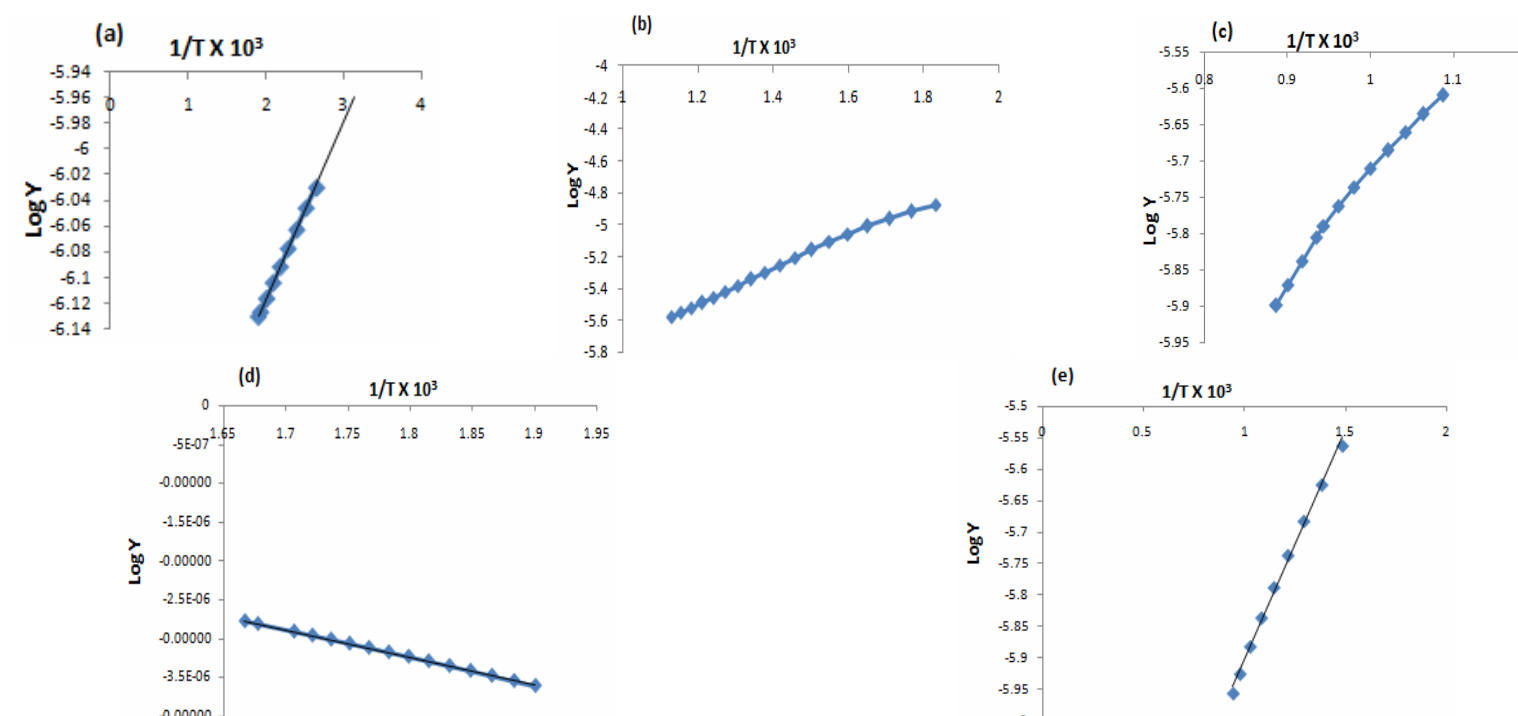

Figure 7: Thermograms of a) $1^{\text {st }}$, b) $2^{\text {nd }}$ and c) $3^{\text {rd }}$ stages of SCB/F; and d) $1^{\text {st }}$ and e) $2^{\text {nd }}$ stages of EGO8:1, respectively 
The removal rate became slow and there was no noticeable increase in the adsorption rate observed after $75 \mathrm{~min}$ for SCB/F and EGO2:1, 45 min for EGO4:1 and EGO6:1, and $60 \mathrm{~min}$ (optimum time for the adsorption process) for EGO8:1 and EGO10:1, respectively. This phenomenon implies that the complexes formed in the early stage of absorption are unstable. The adsorption of $\mathrm{Ni}^{2+}$ to EGO8:1 was found to be much higher than to other EGO samples (R \% = 99.94) and steadily increased until $45 \mathrm{~min}$. This can be attributed to the 2D structure of GO sheets and the presence of large nitrogen content on the GO sheets in the case of EGO8:1, which is easily accessible to the metals, making EGO a strong candidate for metals removal. ${ }^{28}$ The differences in the $\mathrm{Ni}^{2+}$ adsorption behavior of the prepared samples prove that the samples did not have the same morphology.

\section{Effect of temperature}

Research has shown that most removal processes take place at temperatures between 293 and $323 \mathrm{~K}$. Maximizing temperature maximizes the force of the ions to bind to the active sites of the nanocomposite, thus improving the removal efficiency.

The effect of temperature on the $\mathrm{Ni}^{2+}$ ion adsorption capacity of $\mathrm{SCB} / \mathrm{F}$ and $\mathrm{EGO}$ was investigated from 298 to $328 \mathrm{~K}$. All adsorption experiments were performed at fixed initial concentration: $15 \mathrm{mg} / \mathrm{L}$, adsorbent dosage: $20 \mathrm{mg}$; time: 30 min. As shown in Figure 9, when the temperature increases from 298 to $328 \mathrm{~K}$, the removal of $\mathrm{Ni}^{2+}$ by $\mathrm{SCB} / \mathrm{F}$ and EGO samples increased, suggesting that adsorption between $\mathrm{Ni}^{2+}$ and $\mathrm{SCB} / \mathrm{F}$ or EGO samples is an endothermic process. ${ }^{15}$ This can be explained by the nature of the GO molecules. Increasing the temperature will increase the rate of diffusion of $\mathrm{Ni}^{2+}$ ions across the external boundary layer and in the internal pores of the GO particles. The adsorption of $\mathrm{Ni}^{2+}$ ions by $\mathrm{GO}$ derivatives may involve physical and chemical adsorption due to higher temperature, thus an increase in active sites occurs due to bond rupture. ${ }^{14,19}$ In other words, the endothermic reaction is due to the enlargement of pore size and the activation of the GO surface. ${ }^{13}$

Meanwhile the removal of $\mathrm{Ni}^{2+}$ by EGO4:1 decreases, suggesting that the interaction between $\mathrm{Ni}^{2+}$ and EGO4:1 is an exothermic process. ${ }^{7,10}$
This can be explained by the thickness of the boundary layer minimized at high temperature, due to the increased tendency of $\mathrm{Ni}^{2+}$ ions to escape from the GO surface to the solution phase (weak adsorption interaction between GO surface and $\mathrm{Ni2}+$ ion), which involves physical adsorption. ${ }^{7,10}$

\section{Effect of initial concentration}

The concentration of $\mathrm{Ni}^{2+}$ ions may have an effect on its adsorption onto the developed materials. Thus, experiments were carried out with variable initial $\mathrm{Ni}^{2+}$ ions concentrations $(15$, 20,25 and $30 \mathrm{mg} / \mathrm{L}$ ) at the temperature of $398 \mathrm{~K}$, time of $30 \mathrm{~min}$ and adsorbent dosage of $20 \mathrm{mg}$ (Fig. 10). It can be observed from the experimental results that the rate of $\mathrm{Ni}^{2+}$ ions removal increased with the increase of initial $\mathrm{Ni}^{2+}$ ions concentration in the case of EGO2:1, EGO4:1, EGO8 and EGO10:1. This result could be due to the fact that the initial concentration delivers an important driving force to overcome all mass transfer resistance between the solid and liquid phases. The EGO samples contain sufficient exchangeable active sites, so at higher $\mathrm{Ni}^{2+}$ ions concentration, more ions are available for such active sites. The sorption efficiency of $\mathrm{Ni}^{2+}$ ions on EGO2:1, EGO4:1, EGO6:1, EGO8:1 and EGO10:1 increased by 3.87 to $78.42 \%$, as the initial concentration of $\mathrm{Ni}^{2+}$ ions increased from 15 to $30 \mathrm{mg} / \mathrm{L}$.

The percentage of $\mathrm{Ni}^{2+}$ removal decreased with increasing the initial concentration of $\mathrm{Ni}^{2+}$ in the case of SCB/F. The number of exchangeable sites in the $\mathrm{SCB} / \mathrm{F}$ structure and the ratio of $\mathrm{Ni}^{2+}$ to $\mathrm{SCB} / \mathrm{F}$ are the reasons for the decrease in the percentage of $\mathrm{Ni}^{2+}$ removal with an increasing initial concentration of $\mathrm{Ni}^{2+}$. As the ratio of $\mathrm{Ni}^{2+}$ to $\mathrm{GO}$ increases, the exchangeable sites in $\mathrm{GO}$ are saturated, resulting in a decline of the removal percentage. This may be attributed to the lack of sufficient surface area to accommodate the excess $\mathrm{Ni}^{2+}$ available in the solution and the saturation of adsorption sites at higher $\mathrm{Ni}^{2+}$ concentrations. ${ }^{33}$

\section{Kinetic modeling}

Concerning the values of $\mathrm{R}^{2}$ presented in Table 7 , it may be noted that the pseudo-second-order model gave a better fit to the adsorption data than the first-order one for all the samples (Fig. 11). This elucidates that the adsorption processes of 
$\mathrm{Ni}^{2+}$ ions onto $\mathrm{SCB} / \mathrm{F}$ and $\mathrm{EGO}$ samples involved chemisorption. ${ }^{13}$

\section{Adsorption isotherm}

All the isotherms were best fitted to the Langmuir model due to the high value of $\mathrm{R}^{2}$. Thus, it can be concluded that the SCB/F and EGO surfaces are homogeneous, and surface adsorption often occurs in monolayer (Fig. 12, Table 8$){ }^{17}$

\section{Thermodynamic parameters}

The negative value of $\Delta \mathrm{H}$ for EGO4:1 indicates an exothermic process (i.e. the adsorption capacity of GO decreases with increasing temperature), while its positive value

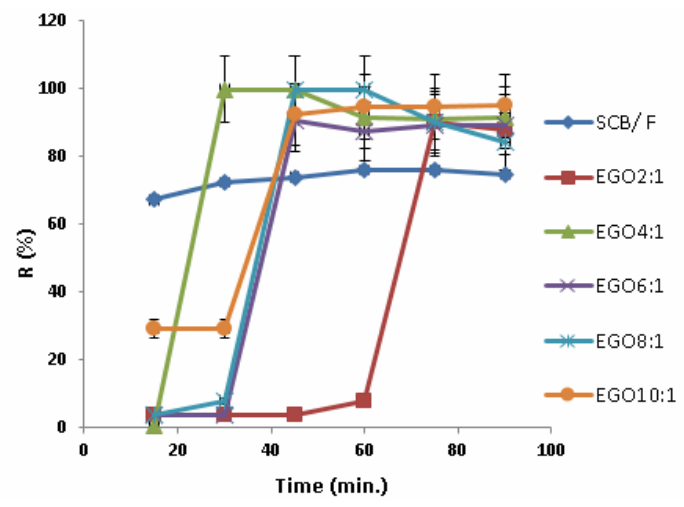

Figure 8: Effect of contact time on removal of $\mathrm{Ni}^{2+}$ by SCB/F, EGO2:1, EGO4:1, EGO6:1, EGO8:1 and EGO10:1 for $\mathrm{SCB} / \mathrm{F}, \mathrm{EGO} 2: 1$, EGO6:1, EGO8:1 and EGO10:1 samples corresponds to an endothermic process (i.e. the adsorption capacity of GO increases with increasing temperature). ${ }^{34}$ The negative values of $\Delta \mathrm{G}$ indicate that the sorption process is spontaneous. ${ }^{34}$ The $\Delta \mathrm{S}$ changes in this study are found to be positive for $\mathrm{SCB} / \mathrm{F}$, EGO2:1, EGO6:1, EGO8:1 and EGO10:1; it means that increased randomness appeared on the GO-solution interface during the exchange of $\mathrm{Ni}^{2+}$ metal ions. ${ }^{15}$ The $\Delta \mathrm{S}$ negative value in EGO4:1 elucidates decreased randomness at the GO-solution interface (Table 9). From these results, it could be concluded that the adsorption onto EGO was more influenced by changes in solution temperature.

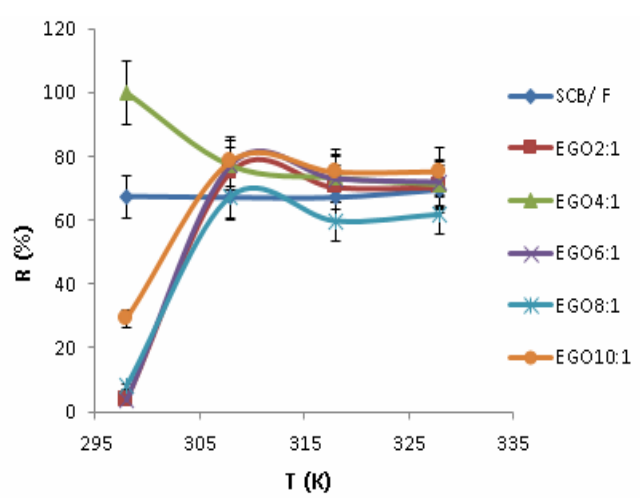

Figure 9: Effect of temperature on removal of $\mathrm{Ni}^{2+}$ using SCB/F, EGO2:1, EGO4:1, EGO6:1, EGO8:1 and EGO10:1

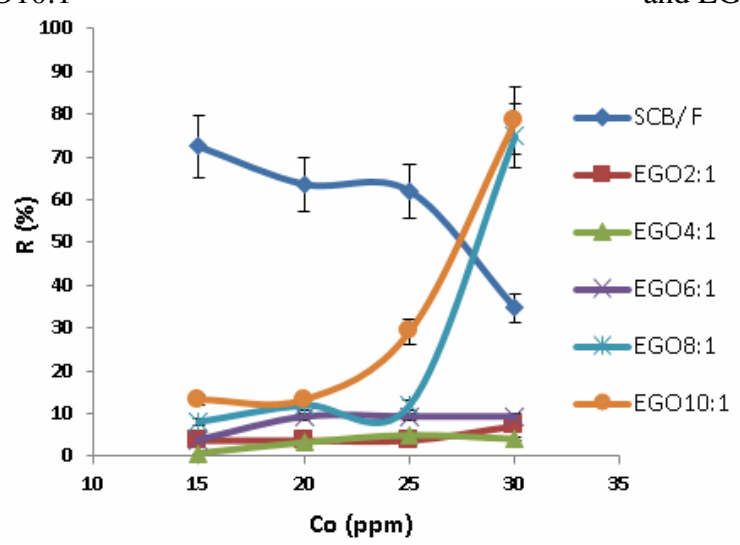

Figure 10: Effect of initial $\mathrm{Ni}^{2+}$ ion concentration on adsorption onto SCB/F, EGO2:1, EGO4:1, EGO6:1, EGO8:1 and EGO10:1 surfaces 
(a)

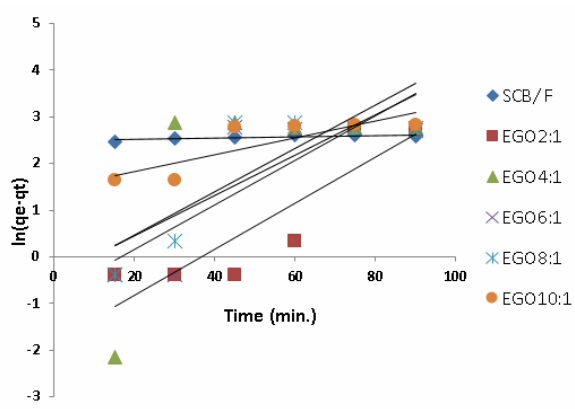

(b)

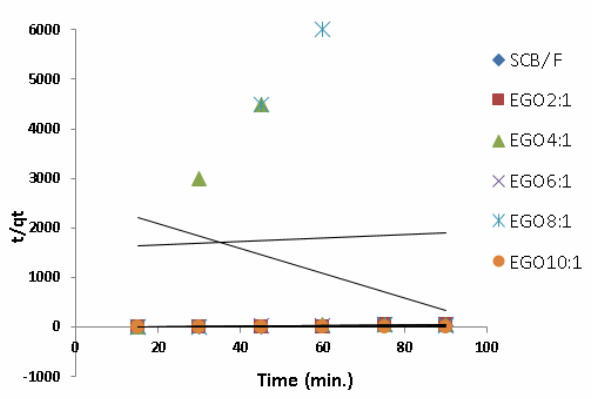

(c)

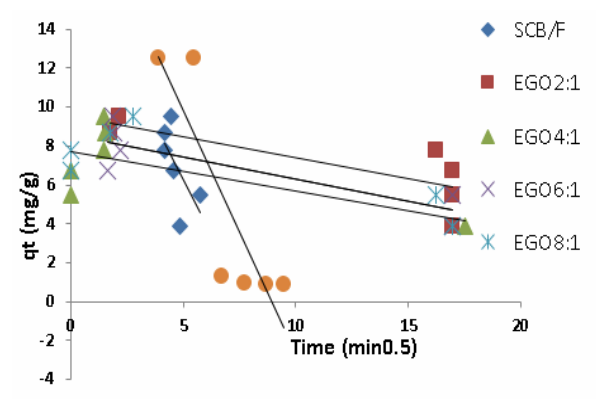

Figure 11: Kinetic parameters of (a) pseudo-first-order and (b) pseudo-second-order reaction for $\mathrm{Ni}^{2+}$ adsorbed onto SCB/F, EGO4:1, EGO6:1, EGO8:1 and EGO10:1 at different time intervals
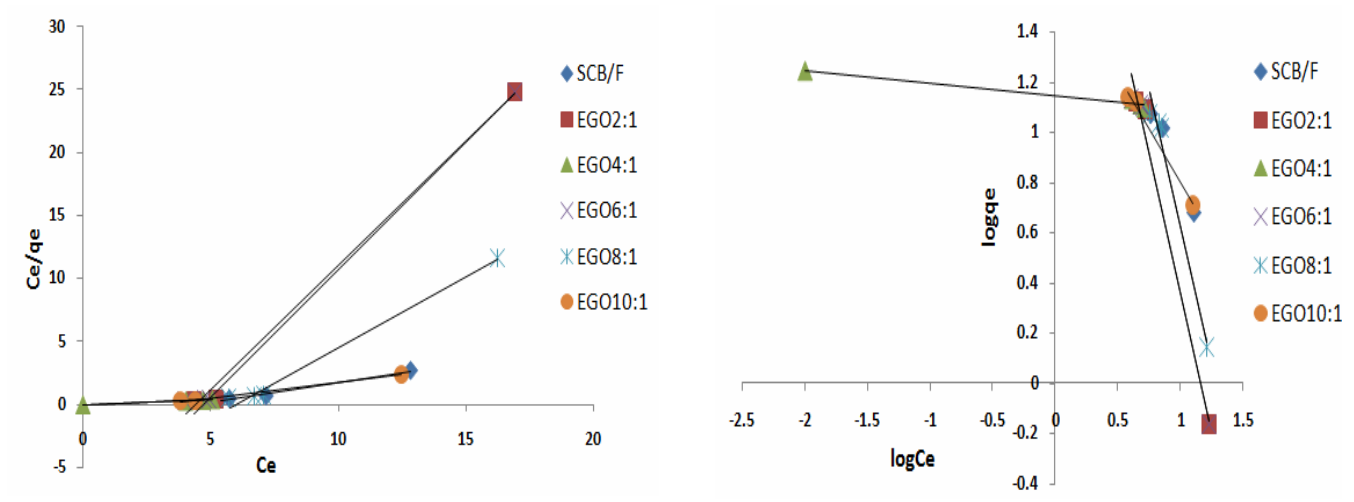

Figure 12: Langmuir isotherm (left) and Freundlich isotherm (right) for $\mathrm{Ni}^{2+}$ ions adsorption onto EGO surfaces (initial concentration $15 \mathrm{mg} / \mathrm{L}$, adsorbent dosage: $20 \mathrm{mg}$; time: $30 \mathrm{~min}$ ) 
HEBAT-ALLAH S. TOHAMY et al.

Table 7

Comparison between the estimated adsorption rate constants, rate constants and correlation coefficients associated with the pseudo-first-order and pseudo-second-order rate

\begin{tabular}{lccccccc}
\hline Kinetic model & Parameter & $\mathrm{SCB} / \mathrm{F}$ & EGO2:1 & EGO4:1 & EGO6:1 & EGO8:1 & EGO10:1 \\
\hline \multirow{4}{*}{ Pseudo-first-order } & $\mathrm{q}_{\text {exp. }}(\mathrm{mg} / \mathrm{l})$ & 13.47 & 15.87 & 17.62 & 16.00 & 17.62 & 16.74 \\
& $\mathrm{q}_{\text {calc. }}(\mathrm{mg} / \mathrm{l})$ & 12.056 & 0.166 & 0.248 & 0.451 & 0.663 & 4.363 \\
& $\mathrm{~K}_{1}\left(\mathrm{~min}^{-1}\right)$ & 0.37 & 0.049 & 0.049 & 0.048 & 0.043 & 0.018 \\
& $\mathrm{R}^{2}$ & 0.647 & 0.639 & 0.410 & 0.684 & 0.674 & 0.697 \\
\hline \multirow{3}{*}{ Pseudo-second-order } & $\mathrm{q}_{\text {calc. }}(\mathrm{mg} / \mathrm{l})$ & 4.084 & 1.586 & 0.0198 & 1.496 & 1.817 & 0.681 \\
& $\mathrm{~K}_{2}(\mathrm{~g} / \mathrm{mg} / \mathrm{min})$ & 0.708 & 0.036 & 0.013 & 0.062 & 0.059 & 0.050 \\
& $\mathrm{R}^{2}$ & 0.981 & 0.960 & 0.766 & 0.982 & 0.846 & 0.969 \\
\hline \multirow{3}{*}{ Intra-particle diffusion } & $\mathrm{k}_{\mathrm{di}}\left(\mathrm{mg} / \mathrm{g} \mathrm{min}{ }^{0.5}\right)$ & -0.18 & -2.90 & -2.18 & -3.20 & -3.12 & -2.48 \\
& $\mathrm{C}_{\mathrm{i}}(\mathrm{mg} / \mathrm{g})$ & 5.95 & 32.09 & 18.92 & 29.33 & 28.09 & 22.18 \\
& $\mathrm{R}^{2}$ & 0.411 & 0.620 & 0.443 & 0.737 & 0.650 & 0.760 \\
\hline
\end{tabular}

Table 8

Langmuir and Freundlich model parameters for adsorption of $\mathrm{Ni}^{2+}$ onto EGO surfaces

\begin{tabular}{lccccccc}
\hline Kinetic model & Parameter & SCB/F & EGO2:1 & EGO4:1 & EGO6:1 & EGO8:1 & EGO10:1 \\
\hline \multirow{2}{*}{ Langmuir } & $\mathrm{q}_{\mathrm{m}}(\mathrm{mg} / \mathrm{g})$ & 3.22 & 11.49 & 13.79 & 13.51 & 14.89 & 13.92 \\
& $\mathrm{R}^{2}$ & 0.984 & 0.996 & 0.996 & 0.996 & 0.989 & 0.998 \\
\hline \multirow{2}{*}{ Freundlich } & $\mathrm{K}_{\mathrm{f}}\left(\mathrm{mg}^{(1-1 / \mathrm{n})} \mathrm{g}^{-1} \mathrm{~L}^{1 / \mathrm{n}}\right)$ & 6.87 & 15.03 & 13.15 & 13.13 & 17.04 & 15.32 \\
& & 0.974 & 0.986 & 0.966 & 0.986 & 0.978 & 0.993 \\
\hline
\end{tabular}

Table 9

Thermodynamic parameters for EGO adsorption of $\mathrm{Ni}^{2+}$ ions

\begin{tabular}{|c|c|c|c|c|c|c|c|}
\hline Parameter & & $\mathrm{SCB} / \mathrm{F}$ & EGO2:1 & EGO4:1 & EGO6:1 & EGO8:1 & EGO10:1 \\
\hline$\Delta \mathrm{S}(\mathrm{kJ} / \mathrm{mole})$ & & 0.04 & 0.32 & -0.51 & 0.32 & 0.22 & 0.16 \\
\hline$\Delta \mathrm{H}(\mathrm{kJ} / \mathrm{mole})$ & & $12 \times 10^{3}$ & $99 \times 10^{3}$ & $-16 \times 10^{4}$ & $10 \times 10^{4}$ & $70 \times 10^{3}$ & $48 \times 10^{3}$ \\
\hline & $298 \mathrm{~K}$ & -1.79 & 7.96 & -18.52 & 7.96 & 6.08 & 2.20 \\
\hline$\Delta \mathrm{G}$ & $308 \mathrm{~K}$ & -1.79 & -2.84 & -3.10 & -3.11 & -1.85 & -3.28 \\
\hline$(\mathrm{kJ} /$ mole $)$ & $318 \mathrm{~K}$ & -0.98 & -2.28 & -2.65 & -2.61 & -1.02 & -2.89 \\
\hline & $328 \mathrm{~K}$ & -2.21 & -2.35 & -2.45 & -2.55 & -1.29 & -3.00 \\
\hline
\end{tabular}




\section{CONCLUSION}

$\mathrm{SCB} / \mathrm{F}$ was treated with EDTA by a hydrothermal reaction. Raman and FTIR analyses proved the cross-linking reaction between the $\mathrm{OH}$ group of $\mathrm{SCB} / \mathrm{F}$ and $\mathrm{NH}_{2}$ of EDTA, forming an amide bond. The pore size, from SEM analysis, demonstrated the porosity of the samples, especially EGO8:1. The decrease in EGO samples crystallinity due to cleavage of the H-bonds during the grafting reaction was proved by X-ray analysis. The TGA/DTG results demonstrated the higher thermal stability of $\mathrm{SCB} / \mathrm{F}$, compared with that of EGO samples.

The adsorption of $\mathrm{Ni}^{2+}$ to EGO8:1 was found to be much higher than to the other types of EGOs and $\mathrm{SCB} / \mathrm{F}$, due to the presence of nitrogen groups acquired from EDTA (Fig. 4), and also due to its higher porosity (Fig. 3). The results of kinetic modeling, adsorption isotherms, and thermodynamic parameters showed that the pseudo-second-order model gave a better fit to the adsorption data of SCB/F and EGO samples and all the isotherms were best fitted by the Langmuir model. The negative values of $\Delta \mathrm{G}$ indicated that the sorption process was spontaneous. The $\Delta \mathrm{S}$ changes in this study were found to be positive for most samples, which means that increased randomness appeared on the GO-solution interface during the exchange of $\mathrm{Ni}^{2+}$ metal ions.

ACKNOWLEDGEMENTS: The authors would like to express their gratitude to the National Research Centre, Egypt, and the Academy of Scientific Research and Technology, Egypt, for financial support of the research activities through Egypt-France Scientific and Technological Cooperation Program (Imhotep).

\section{REFERENCES}

1 S. Wang, H. Sun, H. M. Ang and M. O. Tadé, Chem. Eng. J., 226, $336 \quad$ (2013), http://doi.org/10.1016/j.cej.2013.04.070

2 A. Aghigh, V. Alizadeh, H. Y. Wong, M. S. Islam, N. Amin et al., Desalination, 365, 389 (2015), http://doi.org/10.1016/j.desal.2015.03.024

3 A. Bonilla-Petriciolet, D. I. Mendoza-Castillo and H. E. Reynel-Ávila, "Adsorption Processes for Water Treatment and Purification", Netherlands, Springer, 2017, pp. 1-14, http://doi.org/10.1007/978-3-31958136-1

4 S. Kamel, H. Abou-Yousef, M. Yousef and M. ElSakhawy, Carbohyd. Polym., 88, 250 (2012), https://doi.org/10.1016/j.carbpol.2011.11.090

B. I. Kharisov and O. V. Kharissova, in "Carbon Allotropes: Metal-Complex Chemistry, Properties and
Applications", Springer, 2019, pp. 35-109, http://doi.org/10.1007/978-3-030-03505-1_3

6 S. Kamel, M. El-Sakhawy, B. Anis and H. A. S. Tohamy, Egypt. J. Chem., 62, 593 (2019), http://doi.org/10.21608/ejchem.2019.15173.1919

7 H. A. S. Tohamy, M. El-Sakhawy and S. Kamel, J. Polym. Environ., 29, $859 \quad$ (2020), https://doi.org/10.1007/s10924-020-01920-7

8 M. Nujić and M. Habuda-Stanić, "Toxic Metal Ions in Drinking Water and Effective Removal Using Graphene Oxide Nanocomposite", edited by M. Naushad, Springer, 2019, pp. 373-396, http://doi.org/10.1007/978-3-319-75484-0_15

9 J. Zhao, L. Liu and F. Li, "Graphene Oxide: Physics and Applications", Springer, Berlin, Heidelberg, 2015, pp. 119-135, http://doi.org/10.1007/978-3-662-44829-8_6

10 H. A. S. Tohamy, B. Anis, M. A. Youssef, A. E. Abdallah, M. El-Sakhawy et al., Desalin. Water Treat., 191, $250 \quad$ (2020), http://doi.org/10.5004/dwt.2020.25652

11 M. El-Sakhawy, H.-A. S. Tohamy, A. Salama and S. Kamel, Cellulose Chem. Technol., 53, 667 (2019), https://doi.org/10.35812/CelluloseChemTechnol.2019. 53.65

12 J. Zhang and Z. Cai, U.S. Patent No. 9,540,244, Washington, DC, U.S. Patent and Trademark Office, 2017

13 F. A. Dawodu, G. K. Akpomie and P. C. N. Ejikeme, Res. J. Eng. Sci., 1, 9 (2012), http://www.isca.me/IJES/Archive/v1/i6/2.ISCA-

RJEngS-2012-080.pdf

14 N. Ertugay and E. Malkoc, Pol. J. Environ. Stud., 23, 1995 (2014), http://www.pjoes.com/Issue-62014,429

15 P. S. Kumar and K. Kirthika, J. Eng. Sci. Tech., 4, 351 (2009),

http://jestec.taylors.edu.my/Vol\%204\%20Issue\%204\% 20December\%2009/Vol_4_4_351_363_P.\%20Senthil $\% 20$ Kumar.pdf

16 F. Najafi, O. Moradi, M. Rajabi, M. Asif, I. Tyagi et al., J. Mol. Liq., 208, $106 \quad$ (2015), http://doi.org/10.1016/j.molliq.2015.04.033

17 I. Sheet, A. Kabbani and H. Holail, Energ. Proc., 50, 130

(2014),

http://doi.org/10.1016/j.egypro.2014.06.016

18 M. T. Amin, A. A. Alazba and M. N. Amin, Pol. J. Environ. Stud., 26, $543 \quad$ (2017), http://doi.org/10.15244/pjoes/66963

19 G. M. Al-Senani and F. F. Al-Fawzan, Egypt. J. Aquat. Res., 44, 187 (2018), http://doi.org/10.1016/j.ejar.2018.07.006

20 S. Kanrar, S. Debnath, P. De, K. Parashar, K. Pillay et al., Chem. Eng. J., 306, 269 (2016), http://doi.org/10.1016/j.cej.2016.07.037

21 E. Serag, A. El Nemr and A. El-Maghraby, J. Water Environ. Nanotechnol., 2, 223 (2017), http://doi.org/10.22090/jwent.2017.04.001 
22 M. Kazemnejadi, B. Mahmoudi, Z. Sharafi, M. A. Nasseri, A. Allahresani et al., J. Organomet. Chem., 896, 59

http://doi.org/10.1016/j.jorganchem.2019.05.030

23 A. Romero, M. P. Lavin-Lopez, L. Sanchez-Silva, J. L. Valverde and A. Paton-Carrero, Mat. Chem. Phys., 203, 284 (2018),

http://doi.org/10.1016/j.matchemphys.2017.10.013

${ }_{24}$ H. Nassef, M. Hagar, Z. Malek and A. M. Othman, Materials, 11, 68 https://doi.org/10.3390/ma11010068

25 M. El-Sakhawy, S. Kamel, A. Salama and H.-A. S. Tohamy, Egypt. J. Chem., 60, 181 (2017), https://doi.org/10.21608/ejchem.2017.544.1002

26 S. Liu, H. Zhang, D. Peng, D. Yuan, L. Wu et al., Int. J. Energ. Res., 41, 263 (2017), http://doi.org/10.1002/er.3616

27 M. El-Sakhawy, A. Salama, S. Kamel and H.-A. S. Tohamy, Cellulose Chem. Technol., 52, 749 (2018), https://www.cellulosechemtechnol.ro/pdf/CCT9-

10(2018)/p.749-757.pdf
28 H. V. Tran, T. L. Tran, T. D. Le, H. M. Nguyen and L. T. Dang, Mater. Res. Express, 6, 1 (2019), http://doi.org/10.1088/2053-1591/aae55c

29 M. El-Sakhawy, S. Kamel, A. Salama and H.-A. S. Tohamy, Cellulose Chem. Technol., 52, 193 (2018), https://www.cellulosechemtechnol.ro/pdf/CCT34(2018)/p.193-200.pdf

30 H. A. S. Tohamy, S. Kamel, M. El-Sakhawy, M. A. Youssef, A. E. Abdallah et al., Egypt. J. Chem., 63, 8 (2020), https://doi.org/10.21608/ejchem.2020.22915.2375

31 I. Sengupta, S. Chakraborty, M. Talukdar, S. K. Pal and S. Chakraborty, J. Mater. Res., 33, 4113 (2018), http://doi.org/10.1557/jmr.2018.338

32 S. Bolisetty, M. Peydayesh and R. Mezzenga, Chem. Soc. Rev., 48, 463 (2019), http://doi.org/10.1039/C8CS00493E

33 M. Shafiq, A. Alazba and M. Amin, Sains Malays., 47, 35 (2018), http://dx.doi.org/10.17576/jsm-20184701-05

34 I. H. Lee, Y. C. Kuan and J. M. Chern, J. Chin. Inst. Chem. Eng., 38, 71 (2007), http://doi.org/10.1016/j.jcice.2006.11.001 